\title{
Política dos 3 R's aplicada à gestão de resíduos de televisores no Município de Franca (Estado de São Paulo, Brasil)
}

\section{Eliezer Pessoni Viana, Fernando Dandaro}

Faculdade de Tecnologia de Franca "Dr. Thomaz Novelino". Curso Superior de Tecnologia em Gestão da Produção Industrial. Rua Irênio Grecco, 4580. Parque São Jorge. Franca-SP, Brasil (CEP 14405-191). E-mail: fdandaro@hotmail.com.

Resumo. A logística reversa é um importante instrumento para o atual panorama competitivo das empresas. Nesse trabalho, o foco foi descrever a logística reversa como forma de gestão dos resíduos de produtos de pós-consumo. Assim, o objetivo deste trabalho, realizado em empresas de reparos, vendas, manutenção de televisores e componentes eletrônicos utilizados nesses aparelhos no Município de Franca, foi identificar os principais componentes eletrônicos e aplicar a política dos 3R's como forma de gerenciamento desses resíduos nessas empresas. Para tanto, como procedimentos metodológicos, utilizou-se o levantamento bibliográfico exploratório e a pesquisa de campo de caráter descritivo, com a utilização de questionários e uma entrevista aplicada em empresas de componentes eletrônicos de Franca, obtendo dados para uma análise quantitativa. Como resultado, verificou-se através da pesquisa de campo, a confirmação de que há a falta de gerenciamento na Logística Reversa e aplicação da política dos 3R's quanto à redução, reutilização e reciclagem dos materiais em todas as empresas pesquisadas. Constatou-se que $50 \%$ das empresas pesquisadas praticam a reutilização, $25 \%$ das empresas praticam reutilização e reciclagem e $25 \%$ das empresas não praticam nenhum processo, contribuindo então para que esses resíduos sejam levados ao aterro sanitário da cidade. Sendo assim, foi visto que é necessária a aplicação da Política Nacional dos Resíduos Sólidos (PNRS), políticas dos 3R's e a Logística Reversa, porém de forma adequada.

Palavras-chave: Franca; Logística reversa; PNRS; Política dos 3R's; Televisores.

Abstract. $3 R^{\prime} s$ policy applied to waste management of televisions in Franca Municipality (State of São Paulo, Brazil). The reverse logistics is an important instrument to the current overview of business competitiveness. In this paper the, focus has been to describe the reverse logistics as a way of waste management of post-consumer products. Thus, the objective of this study was, carried out in business for repairs, sales, maintainability of a television and electronic components indicators used in Franca Municipality, to identify the main
Recebido:

29/12/2017

Aceito:

22/04/2018

Publicado:

30/04/2018

Acesso aberto

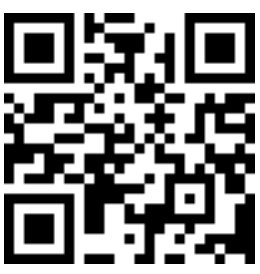

ORCID

(ㄱ) 0000-0001-7758-0232 Eliezer Pessoni Viana

(D) 0000-0001-6530-242X Fernando Dandaro 
components and apply the 3 R's policy as a form of waste management in those companies. There for e as methodological procedures, fully utilized bibliographic and a descriptive field research, the use of questionnaires An interview utilization applied to business of electronic components in Franca, information for a quantitative understanding. As a result, this research, showed the further confirmation of that there is a lack of the reverse logistics and consumer policy should the 3'Rs concerned that the reduction, reuse and recycling of waste of materials in all companies researched, were found to $50 \%$ of companies researched they practice the refurbishing, $25 \%$ of businesses practising refurbishing and recycling and $25 \%$ of the companies not apply any process, then contributed to the to achieve these waste are taken to the sanitary landfill of the city. Thus it is seen that is a decisive application of National Policy of Solid Waste (NPSW), policy of the 3 R's and the reverse logistics, but in an appropriate way.

Keywords: Franca; Reverse logistics; NPSW; 3 R's policy; Television.

\section{Introdução}

Devido ao constante crescimento na demanda de produtos eletrônicos, especificamente televisores de todos os tipos, na exigência do consumidor, na tecnologia dos processos produtivos utilizados e também na matéria prima envolvida, podemos enxergar a grande necessidade de diminuir o uso de matéria prima desses produtos que em sua grande parte é de origem natural.

Pode-se ver claramente que recursos naturais vêm sendo cada vez mais explorados e de forma cada vez menos sustentáveis. Isso vem exigindo das empresas a necessidade de haver melhor aproveitamento dos recursos captados. Por isso o papel da logística reversa de um modo geral é fundamental para se por em prática uma forma de reutilização de recursos que além de diminuir a captação de recursos naturais também pode ser visto como uma forma de agregar valor a esses produtos, reduzir custos de produção utilizando a cadeia logística para reinserir no sistema produtivo os componentes eletrônicos utilizados na fabricação destes produtos.

Hoje é impossível ignorar a importância dos sistemas logísticos nos meios de produção, pois em um futuro próximo a logística nas empresas, em seu propósito, de uma forma ou de outra será o braço que irá assegurar a posição das empresas entre a lucratividade e a falência.

Todos os recursos naturais do planeta são finitos, haverá um momento em que as empresas não terão mais recursos para se explorar, então é importante que essas empresas pratiquem a logística reversa hoje para sobreviver no futuro.

Assim, o objetivo deste trabalho é apresentar a logística reversa como forma de gestão dos resíduos de produtos de pós-consumo, em especial, os componentes de televisores e identificar a aplicação da política dos 3R's como forma de gerenciamento de resíduos em empresas de Franca.

A metodologia utilizada para a realização do trabalho foi levantamento bibliográfico exploratório, por meio de livros, artigos científicos, trabalhos de acadêmicos, material especializado e sites específicos e, também, a pesquisa de campo de caráter descritivo, com aplicação de questionários e entrevistas em empresas de componentes eletrônicos de Franca, obtendo dados 
secundários e primários, respectivamente, para uma análise quantitativa dos dados coletados.

quatro artigo capítulos, abordando respectivamente a concepção logística reversa, os impactos ambientais e a necessidade de gestão, a aplicação das Políticas dos 3R's e o estudo de caso em empresas na cidade de Franca, descrevendo como forma de obter informações sobre a utilização e reutilização de componentes eletrônicos, trazendo resultados importantes para uma melhor análise, que segue disposta nas considerações finais.

\section{Logística reversa}

Compreender a logística empresarial e seus objetivos é uma questão estratégica para as organizações contemporâneas, pois hoje este processo já está evoluído para um sistema logístico reverso. Assim, as empresas necessitam estar atentas para melhor gerenciar seus fluxos de recursos.

Neste sentido, Ballou (2010, p. 18) dispõe que:

A concepção logística de agrupar conjuntamente as atividades relacionadas ao fluxo de produtos e serviços para administrá-las de forma coletiva é uma evolução natural do pensamento administrativo. As atividades de transporte, estoques e comunicações iniciaram-se antes mesmo da existência de um comércio ativo entre regiões vizinhas. Hoje, as empresas devem realizar essas mesmas atividades como uma parte essencial dos seus negócios, a fim de prover seus clientes com os bens e serviços que eles desejam. Entretanto, a administração de empresas nem sempre se preocupou em focalizar o controle e a coordenação coletiva de todas as atividades logísticas. Somente nos últimos anos é que ganhos substanciais nos custos foram conseguidos, graças à coordenação cuidadosa destas atividades. Os ganhos potenciais resultantes de se rever a administração das atividades logísticas está transformando a disciplina numa área de importância vital para uma grande variedade de empresas.

A logística busca um foco para atingir uma qualidade predefinida de serviço ao cliente por meio de uma competência operacional de excelência, para facilitar as operações relevantes de compras, produção, distribuição e marketing, equilibrando as expectativas de serviço e os custos totais em vista de alcançar os objetivos da organização, além de ter uma grande capacidade de resposta ao cliente, controlar desvios de desempenho operacional e minimizar o nível de estoque comprometido, quando bem planejada e integrada dentro da organização (Bowersox e Closs, 2009).

Essa concepção também pode ser aplicar de forma invertida, denominada de logística reversa.

Os primeiros estudos sobre logística reversa são encontrados na década de 70 e 80, tendo seu foco principal relacionado ao retorno de bens a serem processados em reciclagem de materiais, denominados e analisados como canais de distribuição reversos (Leite, 2009, p. 15).

Nota-se que a logística reversa é uma atividade que está entre as mais recentes nos ambientes corporativos, sendo que sua importância esta aumentando cada vez mais, em vista das necessidades que existem atualmente, e as vantagens que puderam ser alcançadas.

Assim, de acordo com Leite (2009), tanto a logística direta quanto a logística reversa tem por função colocar em funcionamento os processos de coleta, transporte e destinação de produtos, serviços ou informações de melhor maneira possível, levando em consideração a eficiência e ou eficácia dentro de um nível desejado, atendendo 
aos requisitos de custo, satisfação, coerência, tempo e fluxo ajustados.

0 mesmo autor esclarece que, devido ao aumento de produção e a obsolescência programada de diversos produtos de um mercado globalizado na atualidade, este possui impacto direto e crescente no meio ambiente, necessitando de maior aplicação da logística reversa, o que justifica a inclusão desta, como estratégia mercadológica nas empresas.

Como solução, Paoleschi (2008) declara que a reciclagem na indústria envolvendo como pilar de sustentação a

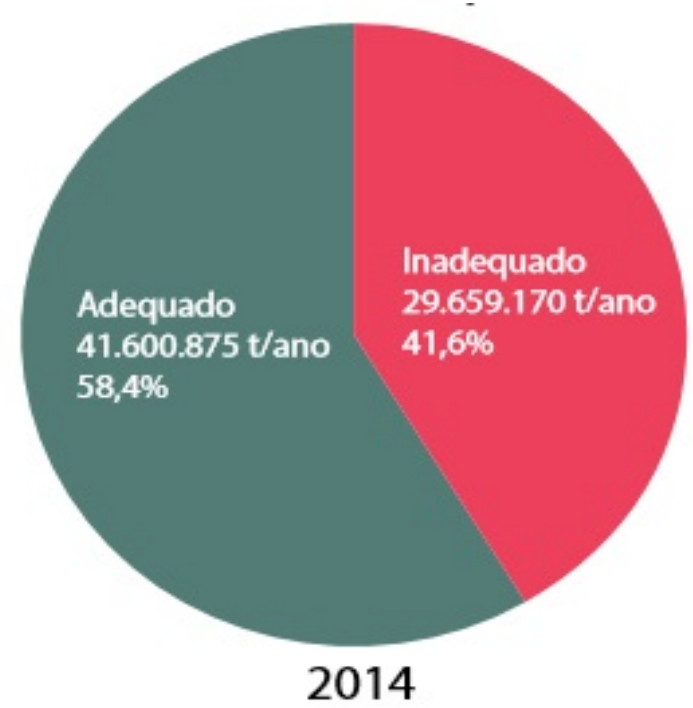

logística reversa, também se trata de grande desafio de origem cultural e educacional que insere pessoas de uma sociedade consumista e também produtos descartáveis nos dias atuais.

Pois a sociedade pautada no consumismo gerou uma grande quantidade de resíduos que precisam de alguma forma ser gerenciados, assim, a logística reversa ganha espaço para atuação. Muitas vezes esses resíduos não foram gerenciados tendo em grande parte uma destinação inadequada (Figura 1).

Figura 1. Representação gráfica da disposição Final dos Resíduos Sólidos Urbanos Coletados no Brasil em Toneladas por Ano (toneladas/ano) nos anos de 2014 e 2015. Fonte: ABRELPE (2016, p. 24).

Como se pode verificar em 2014 a disposição final dos resíduos sólidos no Brasil chegou a cerca de 41.600 .875 milhões de toneladas anuais que tiveram destinação adequada e, cerca de 29.659.170 milhões de toneladas anuais, tiveram destinação inadequada, sendo um valor muito alto em comparação ao resíduo sólido destinado corretamente (Figura 1).

Em 2015 não houve melhora significativa se comparada ao ano anterior em relação à porcentagem de resíduos sólidos destinados corretamente e destinados incorretamente, pois 42.570 .268 milhões de toneladas de resíduos sólidos tiveram destinação adequada, sendo então que cerca de $58,7 \%$ de todo resíduo coletado durante o ano. Porém, $41.3 \%$ de todo o resíduo sólido coletado, teve destinação inadequada chegando a 29.973.482 toneladas anuais (Figura 1). 
Portanto, com um olhar comparativo, pode-se afirmar que houve um aumento de apenas 0,51\% em relação a sua variação percentual de resíduos sólidos corretamente destinados entre os anos de 2014 e 2015. Ainda, como perspectiva operacional para a gestão de resíduos, segundo Leite (2009), as decisões envolvem o uso ferramentas da logística empresarial direta aplicada na logística reversa, em relação a caracterização do produto logístico e sua relevância para as operações na logística, definindo assim, a rede de operações, localização de destinos e origens, modais de transporte, armazenamento, sistemas informativos, aplicação de uma gestão de estoques e outros aspectos. Sabe-se que essas citações e definições na logística reversa, dependendo da abrangência e do setor envolvido, ainda é um conceito imaturo.

Segundo Paoleschi (2008), a logística reversa tem por função tratar dos aspectos de retorno de materiais, produtos ou embalagens ao meio de negócio para alguma forma de reutilização e retorno ao consumidor final.

Já se sabe que a logística reversa possui um papel vital na melhor conservação de recursos naturais mostrando o seu valor na reutilização de produtos, embalagens e materiais. Essa prática irá diminuir possíveis impactos ambientais, melhorando a visão da empresa junto ao consumidor final, fortalecendo a estrutura empresarial e incentivando uma contínua melhoria no desenvolvimento das estratégias da logística reversa.

Guarnieri et al. (2006, p. 124) completam que "a logística reversa pode ser ainda dividida em duas áreas de atuação: logística reversa de pós-venda e logística reversa de pós-consumo".

Para uma melhor visualização desse processo, a Figura 2 que segue, demonstra como os canais de distribuição diretos e reversos podem ter os fluxos relacionados.

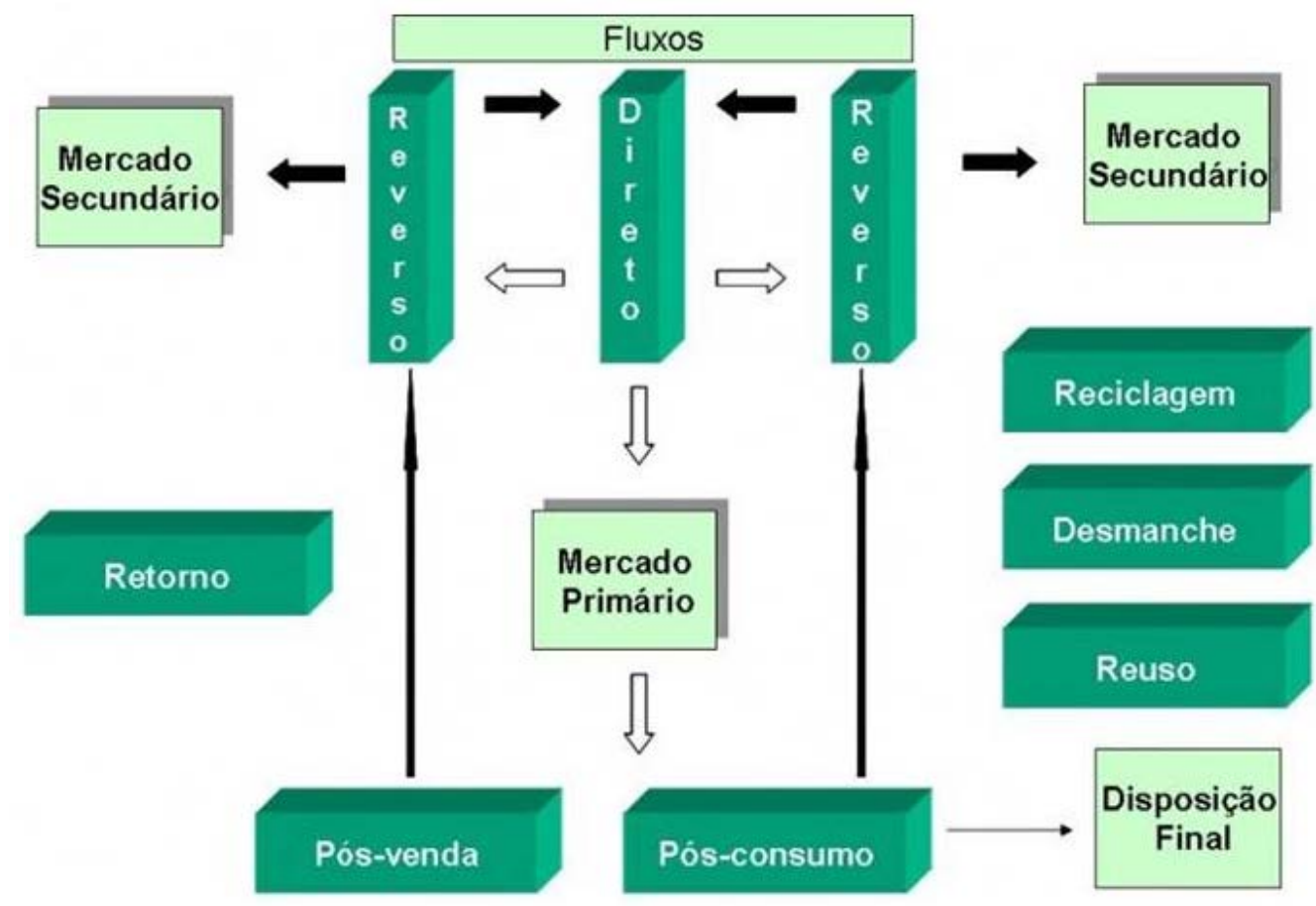

Figura 2. Relação entre os Canais de Distribuição Diretos e Reversos. Fonte: Leite (2009, p. 7). 
Com base na Figura 2, entende-se que os canais diretos de distribuição alcançam um mercado primário, que se inicia na venda até o consumidor final e está interligado aos canais reversos de distribuição reinserindo ao mercado primário produtos ou serviços oriundos dos canais reversos. Já os canais reversos são o pós-venda e pós-consumo derivados do mercado primário, esse canal tem a função de estornar uma solução satisfatória para o retorno ou reaproveitamento de matériasprimas/materiais ao ciclo de produção ou uma correta destinação final de produtos ou materiais não reaproveitados.

Visualizando a importância da logística reversa no processo de gerenciamento de resíduos, fica evidente que uma correta aplicação do canal reverso de distribuição consegue trazer ganhos competitivos para as empresas, promovendo condições para que estas minimizem os impactos ambientais.

\section{eletrônicos}

\section{Gestão ambiental e resíduos}

Os impactos ambientais, atualmente são uma crescente preocupação dos órgãos responsáveis no sentido de elaborar normas e regras de preservação ambiental em relação às atuações das operações, tanto da iniciativa privada quanto de órgãos públicos e em que nível essas operações podem estar diretamente envolvidas com o meio ambiente.

De acordo com a Resolução CONAMA $\mathrm{n}^{\circ}$ 001/1986, "considera-se impacto ambiental qualquer alteração das propriedades físicas, químicas, biológicas do meio ambiente, causada por qualquer forma de matéria ou energia resultante das atividades humanas, que, direta ou indiretamente, venham a afetar: a saúde, a segurança e o bem-estar da população; as atividades sociais econômicas; as condições estéticas e sanitárias do meio ambiente a qualidade dos recursos naturais" (Brasil, 1986).
Segundo Albuquerque (2009), as soluções de problemas ambientais estão diretamente ligadas a conciliar devidas conceitos de crescer e se desenvolver. Nesse caso, se de um lado envolve questões éticas e também sociais, de outro existem questões de nível técnico e competitivo.

Sendo levadas em consideração essas informações, a indústria quando não reciclagem e dentre os produtos de pós-consumo mais reciclados são as garrafas de bebidas alcoólicas e não alcoólicas garrafas de molho em geral, potes em geral entre outros.

Mas, há alguns produtos que não são recicláveis como espelhos, vidros de panela, lâmpada, tubos de televisão e válvulas, ampolas de medicamento, perfumes entre outros.

Sobre o tratamento adequado dos resíduos de pós-consumo, a Política Nacional de Resíduos Sólidos (PNRS), Lei no 12.305/2010, dispõe no art. 9o, parágrafo $2^{\mathrm{o}}$ que:

A Política Nacional de Resíduos Sólidos e as Políticas de Resíduos Sólidos dos Estados, do Distrito Federal e dos Municípios serão compatíveis com o disposto no caput e no $\S 1^{\circ}$ deste artigo e com as demais diretrizes estabelecidas nesta Lei (Brasil, 2010).

Ainda sobre as ações do gerenciamento de resíduos sólidos a PNRS dispõe que:

Conjunto de ações exercidas, direta ou indiretamente, nas etapas de coleta, transporte, transbordo, tratamento e destinação final ambientalmente adequada dos resíduos sólidos e disposição final ambientalmente adequada dos rejeitos, de acordo com plano municipal de gestão integrada de resíduos sólidos ou com plano de gerenciamento de resíduos sólidos, exigidos na forma desta Lei (Brasil, 2010). 
Desta forma, a atuação conjunta da PNRS, da PERS e da PMRS forma uma cadeia de gerenciamento dos resíduos sólidos onde se podem aplicar adequadamente tecnologias disponíveis para aplicação da PNRS (Figura 3).

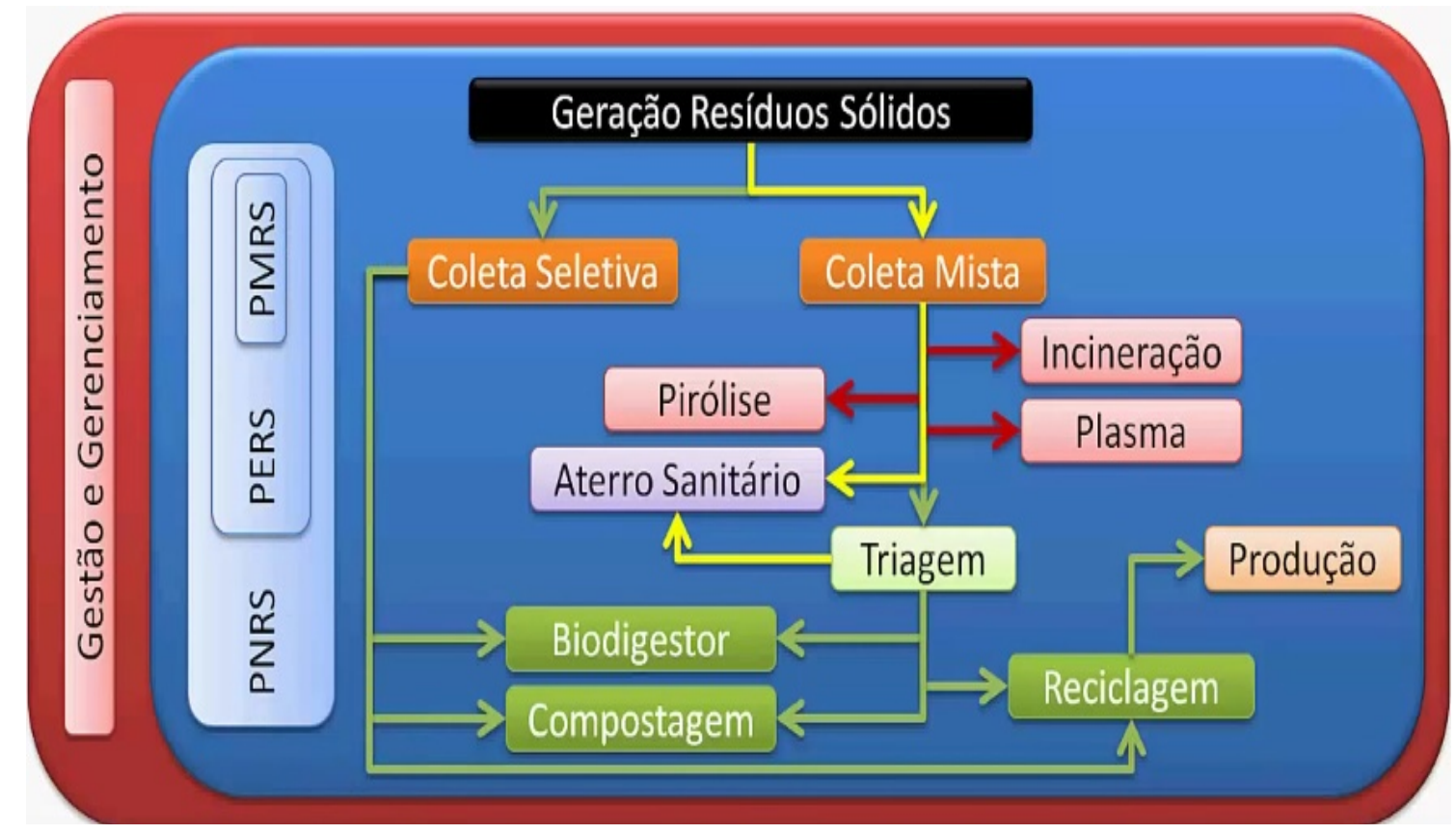

Figura 3. Processo de gestão e gerenciamento de resíduos. Fonte: Machado (2013, p. 1).

Na Figura 3 é evidenciada a forma da coleta e destinação adequada para a aplicação da lei, pois de acordo com Machado (2013), Trigueiro (2013) e Arrigone et al. (2015), pode ser caracterizado do seguinte forma:

- Coleta mista: a coleta mista é a coleta formada por todos os tipos de resíduos juntos, essa coleta que ainda é realizada, não é o melhor caminho para a aplicação da Política Nacional dos Resíduos Sólidos (PNRS);

- Aterro Sanitário: local
providenciado por órgãos públicos
onde é destinada diretamente a
coleta mista;
- Triagem: Em algumas cidades onde
existe um centro de triagem, que
normalmente costumam ser
associações de catadores de resíduos
sólidos, existe uma separação onde é
retirado do que pode ser reciclado
ou reaproveitado de alguma forma;

- Incineração: Várias empresas no Brasil trazem a afirmação de que a coleta mista não precisa ir diretamente para aterros sanitários, podendo haver a separação do material reciclável e transformando os resíduos não reciclados em energia elétrica;

- Plasma: o plasma é um gás superquente onde também pode ser feita a geração de energia através da incineração, no Brasil hoje, várias empresas trabalham com essa tecnologia vendendo a alternativa de geração de energia, que através de um gerador, a energia térmica é convertida em energia mecânica e, posteriormente, em energia elétrica; - Pirólise: Esse processo de dá quando há a ruptura molecular de resíduos mistos previamente selecionados, dessa forma o composto em questão se altera pela ação de alta temperatura. Através da pirólise se obtém o biocombustível; 
- Biodigestor: No biodigestor, a matéria orgânica após ter passado pelo processo de triagem e que pode ser reciclada sofre um processo de aceleramento de sua decomposição sem a presença do oxigênio. Esse deste processo se obtém o biogás;

- Compostagem: É um processo similar ao biodigestor, só que existe a presença de oxigênio no processo, depois do composto maturado através da ação de fungos e bactérias, se obtém o húmus e a partir dele se obtém o adubo orgânico podendo ser utilizado no meio agrícola em geral para a produção de alimentos sem haver a necessidade de utilização dos artificiais;

- Reciclagem: A reciclagem é composta basicamente de resíduos sólidos não orgânicos como o vidro, papel, plástico, metal, entre outros, onde esses resíduos são separados e reenviados para a indústria para uma adequação e reaproveitamento dos mesmos;

- Coleta Seletiva: A coleta seletiva capta os resíduos sólidos que podem ser reaproveitados de alguma forma diretamente na fonte, pulando o processo de aterro sanitário e queima, sendo diretamente levadas para associações de triagem para serem feitas a separação direta dos tipos de materiais para reaproveitamento no biodigestor, compostagem ou reciclagem sendo reenviado para a indústria para adequação e reaproveitamento (nesse caso somente resíduos sólidos não orgânicos).

Ainda, verifica-se que todo este processo deverá estar embasado nas políticas nacionais, estaduais e municipais e resíduos sólidos, conhecidas como Política Nacional dos Resíduos Sólidos (PNRS), Política Estadual dos Resíduos Sólidos (PERS), Política Municipal dos Resíduos Sólidos (PMRS).

Portanto, a falta de gerenciamento dos produtos de pós- consumo entra em desacordo com a lei da PNRS e afeta não só o meio ambiente, mas também ciclos produtivos que podem ser reajustados e melhorados com o reaproveitamento de matéria prima desses produtos.

Sobre a legislação municipal, verificou-se que de acordo com o Diário Oficial da Cde Franca, em 14 de setembro de 2016, foi criada a Lei no 8.435, desenvolvendo o Plano Municipal de Gestão Integrada de Resíduos Sólidos Urbanos (Franca, 2016).

\section{Gerenciamento de resíduos eletrônicos (TV'S)}

Os televisores sendo produtos de valor agregado e produzidos atualmente com tecnologia de ponta, geram resíduos que precisam ser gerenciados adequadamente.

De acordo com Dias (2011), a contaminação do meio ambiente por indústrias ocorreu no início da revolução industrial, acontece que nos processos da indústria, recursos naturais são inseridos nos meios de produção que, pela falta de eficiência interna em seus processos, geram todo tipo de resíduos contaminantes do meio ambiente.

A falta de gerenciamento nos processos produtivos resulta em maior pegada ambiental, maiores custos de produção e menor planejamento da disposição final dos resíduos derivados dessas indústrias ocasionando maior degradação ambiental.

Para uma melhor elucidação sobre os impactos ambientais causados pelo objeto de estudo deste trabalho que é resíduos de televisores, a Tabela 1 , mostra onde se origina alguns resíduos dos equipamentos eletrônicos seus componentes perigosos e também os potenciais risos à saúde humana. Sendo assim, esses resíduos precisam ser gerenciados de acordo com conformidades técnicas. 
Tabela 1. Resíduo de componentes eletrônicos.

\begin{tabular}{|l|c|l|}
\hline Componentes eletrônicos & Componente perigoso & \multicolumn{1}{|c|}{ Riscos à saúde } \\
\hline $\begin{array}{l}\text { Monitores de Computador e } \\
\text { Televisores. }\end{array}$ & Chumbo & $\begin{array}{l}\text { Danos ao sistema nervoso, } \\
\text { circulatório e renal, e } \\
\text { dificuldade de aprendizagem } \\
\text { em crianças. }\end{array}$ \\
\hline $\begin{array}{l}\text { Placas de Circuitos de Impressoras, } \\
\text { transmissores e interruptores, } \\
\text { baterias de produtos eletrônicos. }\end{array}$ & Mercúrio & $\begin{array}{l}\text { Danos permanentes ou fatais } \\
\text { ao cérebro e rins. }\end{array}$ \\
\hline $\begin{array}{l}\text { Interruptores, transmissores e } \\
\text { placas de circuito. }\end{array}$ & Arsênio & $\begin{array}{l}\text { Danos pequenos à pele, pulmão } \\
\text { e câncer linfático; conhecido } \\
\text { agente cancerígeno para os } \\
\text { seres humanos. }\end{array}$ \\
\hline $\begin{array}{c}\text { Baterias de equipamentos } \\
\text { eletrônicos e cabos, placas de } \\
\text { circuito. }\end{array}$ & Cádmio & $\begin{array}{l}\text { Danos ao rim, pulmão e câncer } \\
\text { de próstata. }\end{array}$ \\
\hline
\end{tabular}

Fonte: Gerbase e Oliveira (2012).

Sendo assim, esses resíduos precisam ser gerenciados de acordo com conformidades técnicas.

$\mathrm{Na}$ Tabela 1 pode-se salientar que, os monitores de TV possuem resíduos como o chumbo, mercúrio, arsênio e cádmio que pode trazer prejuízos ambientais e também à saúde humana. Assim, estes possuem características específicas como:

- Chumbo: presente nos monitores de Tv provoca danos ao sistema nervoso, circulatório, renal e também dificuldade de aprendizagem em crianças;

- Mercúrio: podendo estar presentes em placas de circuito impresso de Tv's, transmissores, baterias de produtos eletrônicos e podem causar danos permanentes ou fatais ao cérebro e rins;

- Arsênio: também se encontra em placas de circuito impresso, transmissores de Tv's causando danos à pele, pulmão e câncer linfático, é um conhecido agente cancerígeno para os seres humanos;

- Cádmio: esse elemento químico pode ser encontrado nas baterias dos equipamentos eletrônicos, também em cabos e placas de circuito impresso controladoras dos atuais sistemas de processamento de imagens e informações em smart Tv's modernas.

Por esses motivos, a prática de boa gestão no gerenciamento dos resíduos eletrônicos de Tv's causará impactos positivos na preservação da saúde humana e no seu modo de vida.

Desta maneira, torna-se imprescindível que se preze pela consciência no controle do consumo abusivo dos produtos eletrônicos de uma forma mais eficiente, diminuindo a geração de resíduos eletrônicos de Tv's, havendo então a participação colaborativa da sociedade com o meio ambiente.

Ainda de acordo com o IBGE (2015), pode-se verificar o consumo de aparelhos televisores nos últimos anos, quando foi realizada a pesquisa nacional por amostra de domicílios PNAD suplementar 2013 o seguinte:

No Brasil, dos 65,1 milhões de domicílios, 97,2\% (63,3 milhões $)$ tinham Tv. Havia 103,3 milhões de aparelhos de Tv: 38,4\% de tela fina e $61,6 \%$ de tubo. A Tv de tubo esteve em 54,5 \% dos domicílios que tinham Tv no país (IBGE, 2015, p, 7). 
Sendo assim, pode-se verificar visualmente através da pesquisa realizada pelo IBGE (Figura 3), a predominância dos televisores de tubo.

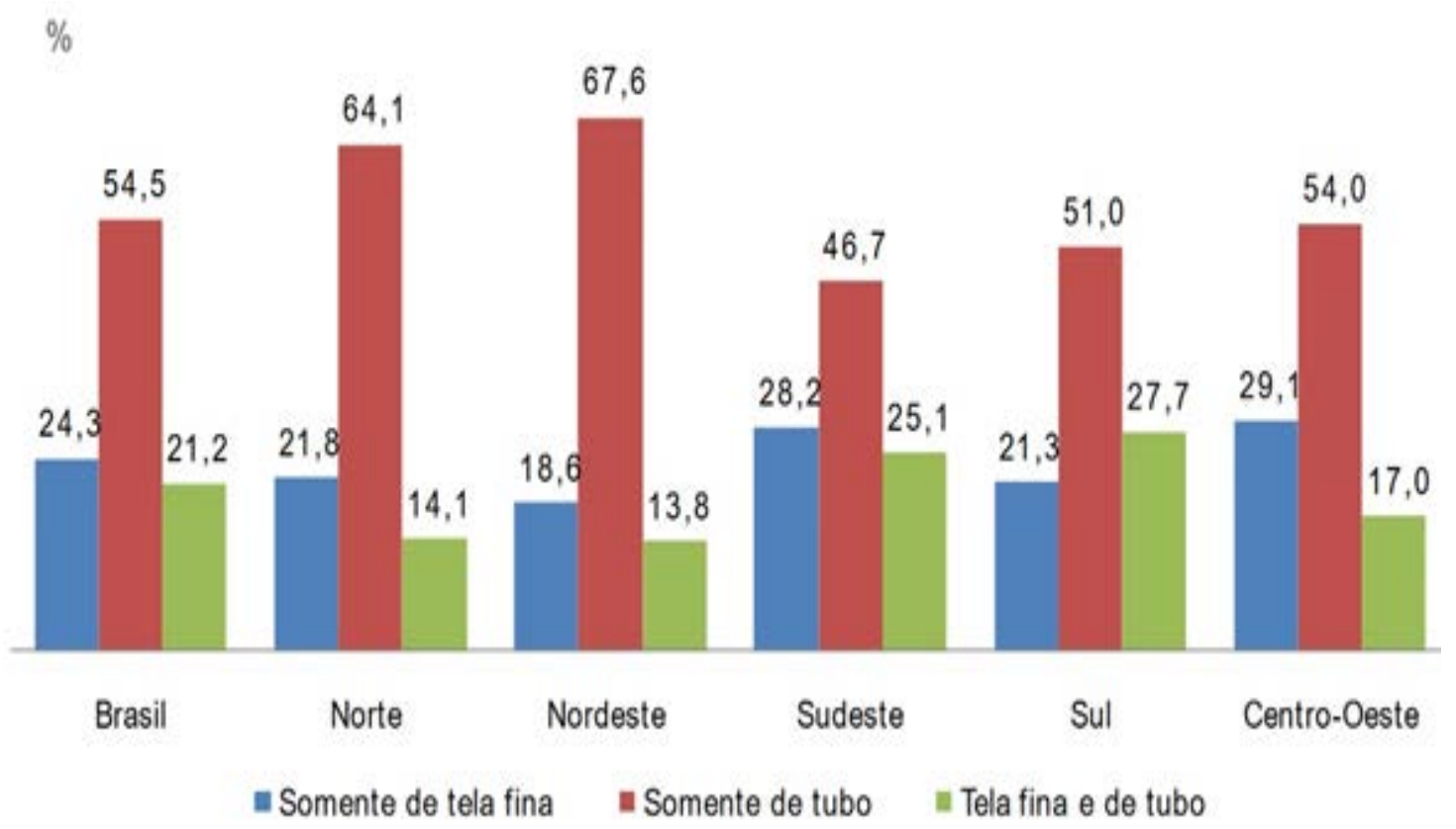

Figura 3. Distribuição dos domicílios com televisores, por região e tipo de televisor (\%). Fonte: IBGE (2015).

De acordo com alguns fabricantes, as placas de um televisor possui um tempo de vida útil de mais ou menos 40.000 a 90.000 horas (seguidas), o que representa entre 4 e 10 anos ligada. Evidentemente, isto é uma estimativa teórica que na realidade não vemos na prática; ou seja, devido à obsolescência programada. Em sua maioria os televisores atuais são construídos com apenas 3 placas de circuitos impressos que que juntas realizam todo o trabalho de funcionamento.

Nos televisores de led, os principais defeitos apresentados são imagem escura, som sem imagem, liga e desliga rapidamente, imagem sem som também podem apresentar manchas na tela.

Nas telas de led existe um problema no emissor led de cor azul que não emite luz adequada se comparado ao emissor vermelho e verde (RGB), mas de acordo com alguns fabricantes os modelos mais recentes de telas led podem chegar a 100.000 horas de uso.

Com base na pesquisa disposta na Figura 7, é possível perceber o grande número de televisores que estão presentes em domicílios de todo o Brasil, o que deixa claro a importância de gerenciar os resíduos sólidos que serão gerados dessa grande quantidade de televisores, pois, com a evolução dos aparelhos, estes tornam-se cada vez mais descartáveis, influenciando a geração de resíduos sólidos que poderão impactar o meio ambiente, exigindo políticas adequadas de redução, reutilização e reciclagem.

\section{Política do 3r's (reduzir, reutilizar e reciclar) \\ A política dos 3R's pode ser} resumida em redução do consumo, 
reutilização de produtos e também na reciclagem de produtos para um melhor aproveitamento dos materiais envolvidos nesse processo.

0 tratamento e a disposição de resíduos constituem-se, na maioria dos casos, em atividades complexas e caras, razões para se procurar a minimização de sua geração e redução de seus impactos sobre o meio ambiente (Moura, 2008, p. 289).

Percebe-se que a redução da geração de resíduos irá favorecer a redução dos impactos ao meio ambiente provocados pelo consumismo mal gerenciado da sociedade moderna, fatores ainda mal aplicados no sistema produtivo atual.

Um caminho para a solução dos problemas relacionados com o lixo é apontado pelo Princípio dos 3R's Reduzir, Reutilizar e Reciclar. Fatores associados com estes princípios devem ser considerados, como o ideal de prevenção e não geração de resíduos, somados à adoção de padrões de consumo sustentável, visando poupar os recursos naturais e conter o desperdício (Brasil, 2017, p. 1).

0 princípio dos 3R's se utiliza de fatores relacionados a produção de modo a viabilizar os processos envolvidos, para aplicar as técnicas e soluções de redução reutilização e reciclagem de produtos de pós consumo ou matéria prima já processada para garantir menor desperdício de recursos naturais e energia, trabalhando com meios padronizados melhorando a eficiência de produtiva.

Assim, Machado (2013) destaca os objetivos de cada um dos 3R's, a saber:

\footnotetext{
- Reduzir é ligar diretamente os processos de inovação em tecnologia, para diminuir a geração de resíduos sólidos na fonte
}

buscando aplicar melhor eficiência na produção de bens ou serviços, mas também na criação de novos bens ou serviços com aplicações semelhantes, porém, mais eficientes; - Reutilizar: a reutilização dos resíduos sólidos tem como principal finalidade a prolongação de vida útil de um determinado produto inserido no mercado. Portanto os produtos com a aplicabilidade de reutilização precisam possuir controle de quantos ciclos produtivos os mesmos poderão atravessar de forma que isso não afete as suas principais características;

- Reciclar: a reciclagem tem como principal objetivo a reintrodução dos resíduos gerados por todos os setores da sociedade no ciclo de produção, sofrendo processos de transformação dos resíduos sólidos envolvendo alterações em suas propriedades físicas, biológicas e também físico-químicas, sendo então esses resíduos transformados tanto em novos produtos quanto insumos.

De acordo com Machado (2013), a disposição de produto/material se trata de um dos 3R's que são o processo de redução, que se enquadra no bloco de não geração havendo então a não geração primária, redução na fonte e reutilização, nesta etapa concorda que ainda não existe a geração de resíduos sólidos.

Como solução para a redução de geração de resíduos, pode-se aplicar ações na extração da fonte dos recursos ou, caso seja possível, modificar processos ou substituindo a própria matéria prima por outra, obtendo assim, um melhor desempenho em consideração à geração dos resíduos. Unindo-se a isso é incrementada a reutilização quando se projeta produtos mais confiáveis e duráveis e, além disso, os componentes ou partes reaproveitadas terão melhores condições para aplicação do reuso que, paralelamente a esse processo ainda pode-se utilizar mecanismos de reciclagem. Para tanto, é preciso analisar 
todo o ciclo de vida do produto verificando vantagens em economia de recurso e também energia (Moura, 2008).

Quanto às vantagens da coleta seletiva e da reciclagem essas são muitas. Além de evitar o desperdício de materiais que ainda podem ser reutilizados, ao se separar o lixo e enviar o material reciclável para um reaproveitamento nas indústrias, isso irá diminuir a quantidade de lixo que precisará ser armazenado e tratado pelos serviços públicos. (Instituto Akatu, 2011).

Assim, fica explícito que sustentabilidade:

É um processo de transformação no qual a exploração dos recursos, a direção dos investimentos, a orientação do desenvolvimento tecnológico e a mudança institucional se harmonizam e reforçam o potencial presente e futuro, a fim de atender às necessidades e aspirações humanas (Dias, 2011, p. 36-37).

Partindo do princípio de que a sustentabilidade, relacionada ao meio ambiente está pautada nas ações de redução, reutilização e reciclagem, estas são entendidas como políticas, que juntas, podem promover um progresso saudável, respeitando sempre a relação entre o consumo necessário e o consumo desejado. A aplicação de melhores processos para a otimização de matériaprima, energia e produto economicamente viável à reciclagem, torna mais possível um melhor gerenciamento do consumo.

Diante desse contexto, o objetivo da pesquisa nesse trabalho pretende analisar a aplicação da política dos 3'Rs no consumo e gestão de resíduos de televisores na cidade de Franca-SP a partir de um estudo de caso.

\section{Estudo de caso}

Para que haja uma contextualização dessa pesquisa, foi abordada a afirmativa de que hoje na cidade de Franca algumas das grandes lojas físicas de varejo como Magazine Luiza, Casas Bahia, Lojas Xavier, Comercial São Jorge, Lojas Cem e WalMart disponibilizam para a venda, grande quantidade de aparelhos televisores e esses precisam de um gerenciamento adequado dos resíduos sólidos gerado pelos mesmos.

Nesse estudo, foram pesquisados oito estabelecimentos que possivelmente praticam a captação e reparos de aparelhos televisores. Levando em consideração que não há mais a possibilidade de reparo ou reaproveitamento, foi investigado sobre o tipo de distinção que é praticado por cada um dos estabelecimentos.

0 motivo da indicação desses estabelecimentos foi em função de seu posicionamento geográfico, pois estes abrangem diferentes regiões estratégicas de grande concentração de população na cidade. Sendo assim, é possível que haja um escoamento natural da demando por reparos ou reaproveitamentos dos televisores consumidos em Franca, justificando o motivo da escolha dos estabelecimentos descritos abaixo:

- Empresa A;

- Empresa B;

- Empresa C;

- Empresa D;

- Empresa E;

- Empresa F;

- Empresa G; e

- Empresa H.

Dessa forma, pode-se ter uma melhor visão da participação dessas empresas na captação dos televisores e se as mesmas praticam uma correta 
responsabilidade ambiental com relação à destinação de possíveis resíduos sólidos gerados através da captação desses produtos pelas mesmas.

\section{Metodologia da pesquisa}

Para a realização do trabalho, foi utilizado o levantamento bibliográfico de caráter exploratório a partir de livros, artigo científico, trabalhos acadêmicos e sites especializados e, também, pesquisa de campo descritiva com aplicação de questionário, obtendo respectivamente dados secundários e primários, oportunizando uma análise quantitativa e qualitativa.

Como instrumento de pesquisa, utilizou-se um questionário organizado em duas partes, sendo que a primeira faz a identificação do respondente e a segunda, investiga sobre o objeto de pesquisa, contendo seis questões, sendo duas fechadas, três semiabertas e uma questão aberta, conforme segue disponível no Apêndice A.

De acordo com Marconi e Lakatos (2011), o questionário é um instrumento de coleta de dados por uma série ordenada de perguntas, que devem ser respondidos de forma escrita e sem a presença do entrevistado. É importante que o entrevistado, saiba da natureza da pesquisa, sua importância e necessidade de se obter as respostas.

0 foi questionário foi aplicado junto aos colaboradores das empresas pesquisas, no período de 29 de maio a 2 de junho de 2017.

Depois que houve o procedimento de coleta de dados pode ser iniciado uma análise do processo para uma melhor compreensão dos dados obtidos, e dessa forma, é possível reconhecer os resultados.

Sendo assim, considerando o questionário, as informações coletadas podem ser apresentadas obtendo uma melhor interpretação e análise dos resultados.

Para uma boa coleta de dados e, consequentemente, a análise dos mesmos, fez-se necessário a abordagem de forma aleatória de pessoas que colaboraram com o preenchimento do questionário especificamente formulado para a realização desta pesquisa que segue, abordando as características dos respondentes e das empresas no segmento de reparos e manutenção em televisores, vendas de televisores, prestação de serviços que responderam o questionário (disponível no apêndice A), definindo a legitimidade do trabalho e a metodologia do mesmo.

Assim, na Tabela 2, segue a caracterização das empresas e dos respondentes.

Portanto, a Tabela 2, revela que essas empresas trabalham com vendas e prestação de serviços, mas nem todas realizam tarefas importantes como um possível processo de aplicação da política dos 3 R's com relação à gestão de resíduos de televisores de cada empresa envolvida na pesquisa analisando os resultados obtidos.

Na Tabela 3 pode-se visualizar a quantidade de televisores que cada estabelecimento recebe mensalmente para o descarte. 
Tabela 2. Caracterização da empresa e do respondente.

\begin{tabular}{|l|c|c|c|c|c|c|}
\hline Empresa & $\begin{array}{c}\text { Função do } \\
\text { Entrevistado }\end{array}$ & $\begin{array}{c}\text { Ano de } \\
\text { Fundação }\end{array}$ & $\begin{array}{c}\text { Ramo de } \\
\text { Atividade }\end{array}$ & $\begin{array}{c}\text { Apenas } \\
\text { Presta } \\
\text { Serviços }\end{array}$ & $\begin{array}{c}\text { Presta } \\
\text { Serviços/ } \\
\text { Vendas de } \\
\text { Aparelhos }\end{array}$ & $\begin{array}{c}\text { Serviços/ } \\
\text { Vendas/ } \\
\text { Componentes/ } \\
\text { Aparelhos }\end{array}$ \\
\hline Empresa A & Proprietário & 1987 & $\begin{array}{c}\text { Vendas/ } \\
\text { Serviços }\end{array}$ & Não & Sim & Não \\
\hline Empresa B & Administrador & 2008 & $\begin{array}{c}\text { Vendas/ } \\
\text { Serviços }\end{array}$ & Não & Sim & Não \\
\hline Empresa C & Proprietário & 2002 & $\begin{array}{c}\text { Vendas/ } \\
\text { Serviços }\end{array}$ & Não & Sim & Não \\
\hline Empresa D & Proprietário & 1986 & $\begin{array}{l}\text { Vendas/ } \\
\text { Serviços }\end{array}$ & Não & Sim & Sim \\
\hline Empresa E & Proprietário & 1983 & $\begin{array}{l}\text { Vendas/ } \\
\text { Serviços }\end{array}$ & Não & Sim & Sim \\
\hline Empresa F & Vendedor & 2007 & $\begin{array}{l}\text { Vendas/ } \\
\text { Serviços }\end{array}$ & Não & Sim & Sim \\
\hline Empresa G & Vendedor & 2003 & $\begin{array}{l}\text { Vendas/ } \\
\text { Serviços }\end{array}$ & Não & Não & Sim \\
\hline Empresa H & Vendedor & 2012 & $\begin{array}{l}\text { Vendas/ } \\
\text { Serviços }\end{array}$ & Não & Não & \\
\hline
\end{tabular}

Tabela 3. Quantidade de televisores recebidos por mês para descarte.

\begin{tabular}{|l|c|}
\hline Empresas & Respostas \\
\hline 1) Empresa A & Até 5 unidades \\
\hline 2) Empresa B & Até 5 unidades \\
\hline 3) Empresa C & Até 5 unidades \\
\hline 4) Empresa D & Mais de 21 unidades \\
\hline 5) Empresa E & De 11 a 20 unidades \\
\hline 6) Empresa F & Até 5 unidades \\
\hline 7) Empresa G & Até 5 unidades \\
\hline 8) Empresa H & Possui parceria com a empresa A (indica o envio para a mesma) \\
\hline
\end{tabular}

Percebe-se que seis das oito empresas pesquisadas não possui captação relevante quanto ao número de aparelhos para descarte ou algum tipo de reaproveitamento, visto que recebem apenas cinco televisores por mês. Esse motivo pode ser relacionado à desinformação da sociedade com a relação à importância de se realizar o descarte dos aparelhos de televisores em locais que deveriam estar preparados para esse fim.

A empresa E recebe por volta de 18 televisores por mês para serem descartados, essa informação foi passada diretamente por um dos sócios proprietários da empresa. Um resultado relevante é associado à empresa $\mathrm{D}$ que possui um maior fluxo desses aparelhos para descarte, que gira por volta de 60 televisores em média para serem descartados mensalmente.

Sendo assim, essas empresas antes de realizarem o descarte verificam uma possível reutilização de um determinado número de componentes que julgam poder ser reaproveitados (Tabela 4). 
Tabela 4. Número de componentes que podem ser reutilizados por televisor.

\begin{tabular}{|l|c|}
\hline Empresas & Quantidade \\
\hline 1) Empresa A & 3 peças \\
\hline 2) Empresa B & 3 a 5 peças \\
\hline 3) Empresa C & 3peças \\
\hline 4) Empresa D & 3 a 10 peças \\
\hline 5) Empresa E & 3 peças \\
\hline 6) Empresa F & 3 peças \\
\hline 7) Empresa G & 3 peças \\
\hline 8) Empresa H & Não opinou \\
\hline
\end{tabular}

Como disposto na Tabela 4 acima a Empresa B e a Empresa D possuem um melhor nível de reaproveitamento de possíveis componentes como placas de circuito micro processadas, diodos emissores de luz (leds) e alguns componentes de tamanho regular como circuitos integrados, capacitores e resistores.

As empresas A, C, E, F e G não fazem uma boa reutilização dos componentes, reaproveitando uma média de 3 peças cada uma por televisor coletado, a empresa $\mathrm{H}$ não opinou sobre 0 assunto.

Componentes de pequeno tamanho que são o caso dos componentes smd's já são mais difíceis de serem reaproveitados de vidro a sua maior fragilidade e complexidade no manuseio dos mesmos. Os resíduos sólidos resultantes de um não reaproveitamento nesse caso deveriam ser destinados para descarte a um local adequado quando na impossibilidade de uma possível reciclagem dos materiais.

Observando a relevância na questão do descarte correto, essas empresas foram questionadas quanto à forma de destinação de aparelhos televisores ou peças (Tabela 5).

A empresa A e empresa B informaram que os resíduos dos aparelhos televisores e peças são coletados pelo processo de coleta seletiva praticada pela atual prestadora do serviço de coleta de lixo na cidade de Franca. Já as empresas C, D e E possuem seus próprios parceiros que coletam os aparelhos e peças, mas nenhuma das três empresas sabe a destinação final dos resíduos que não são reaproveitados ou reutilizados.

Tabela 5. Existência de procedimento adequado para a destinação de aparelhos de televisores ou peças.

\begin{tabular}{|l|l|}
\hline Empresas & \multicolumn{1}{|c|}{ Destinação de aparelhos televisores ou peças } \\
\hline 1) Empresa A & A Coleta seletiva Retira os Aparelhos. \\
\hline 2) Empresa B & $\begin{array}{l}\text { Aparelhos e peças são recolhidos pela atual empresa de coleta de lixo na } \\
\text { cidade de Franca. }\end{array}$ \\
\hline 3) Empresa C & $\begin{array}{l}\text { Aparelhos e peças são coletados por um responsável de um popularmente } \\
\text { chamado ferro velho. }\end{array}$ \\
\hline 4) Empresa D & $\begin{array}{l}\text { Foi formada uma parceria onde um responsável coleta todos resíduos não } \\
\text { reaproveitados e nem reciclados pela empresa. }\end{array}$ \\
\hline 5) Empresa E & $\begin{array}{l}\text { Resíduos são coletados por um responsável do ferro velho do localizada no } \\
\text { bairro Jardim Aeroporto em Franca. }\end{array}$ \\
\hline 6) Empresa F & $\begin{array}{l}\text { Resíduos são Coletados por uma empresa privada especializada em lixo } \\
\text { eletrônico. }\end{array}$ \\
\hline 7) Empresa G & Negou-se a prestar esclarecimentos sobre essa questão. \\
\hline 8) Empresa H & Envia os Aparelhos e peças para o seu parceiro empresa A \\
\hline
\end{tabular}


Em observação ao descontentamento do sócio proprietário da empresa $E$ onde informou que devido à demora do serviço de coleta seletiva oferecido pela prefeitura de Franca em fazer a captação dos aparelhos televisores e peças, o mesmo foi obrigado a fazer uma pareceria com um ferro velho de Franca para fazer a retirada dos aparelhos e peças não reutilizados ou reaproveitados, pois não avia espaço para o armazenamento dos mesmos.

A empresa $F$ informou através de um vendedor balconista que seus resíduos de aparelhos e peças são coletados por uma empresa especializada na coleta de lixo eletrônico. A empresa $\mathrm{G}$ por meio de um responsável se negou a prestar esclarecimentos e a empresa $\mathrm{H}$ envia seus aparelhos para o seu parceiro empresa A, para então serem feitos os devidos descartes da mesma quando necessário.

Visto que, o processo de descarte precisaria estar alinhado com a Política Nacional dos Resíduos Sólidos (PNRS), as empresas foram questionadas sobre $\mathrm{o}$ conhecimento dessa lei de controle de resíduos, com demonstrado na Tabela 6 a seguir:

Tabela 6. Conhecimento da Política Nacional de Resíduos Sólidos.

\begin{tabular}{|l|c|}
\hline Empresas & Respostas \\
\hline 1) Empresa A & Não \\
\hline 2) Empresa B & Não \\
\hline 3) Empresa C & Não \\
\hline 4) Empresa D & Não \\
\hline 5) Empresa E & Sim. Possui um pouco de conhecimento sobre a PNRS. \\
\hline 6) Empresa F & Sim. Possui um pouco de conhecimento sobre a PNRS. \\
\hline 7) Empresa G & Não \\
\hline 8) Empresa H & Não \\
\hline
\end{tabular}

De acordo com a Tabela 6, seis das oito empresas não possuem conhecimento sobre a Política Nacional dos Resíduos Sólios(PNRS),porém, essas empresas já deveriam ter ciência dos principais aspectos da PNRS. Os outros dois possuem pelo menos um pouco de conhecimento nessa área, especificamente, sobre a questão de separação de resíduos.

Sabendo da PNRS deve-se levar em consideração que a logística reversa pode estar diretamente alinhada ao sistema, dessa forma é preciso compreender o que é a logística reversa e sua contribuição para a gestão dos resíduos sólidos, em especial, de aparelhos televisores e peças.

Tratando-se de logística reversa nenhuma das empresas pesquisadas compreende seu funcionamento, pois existe a falta de disseminação da importância da logística reversa e que a mesma é fundamental para o fluxo e forma de destinação de resíduos sólidos, neste caso, de aparelho de televisores e componentes.

Deve-se levar em consideração que a logística reversa é aplicada quando um consumidor movimenta os parelhos televisores usados até uma dessas empresas para o descarte. Assim, está sendo praticada uma logística reversa indireta por não haver a participação do fabricante de forma direta.

Para tanto, as empresas foram questionadas quanto a prática da política dos 3R's em seu processo de gestão (Tabela 7). 
Tabela 7. Utilização da política dos 3R's.

\begin{tabular}{|l|c|}
\hline Empresas & Processos aplicados \\
\hline 1) Empresa A & Reutilização e Reciclagem \\
\hline 2) Empresa B & Reutilização \\
\hline 3) Empresa C & Reutilização \\
\hline 4) Empresa D & Reutilização \\
\hline 5) Empresa E & Reutilização \\
\hline 6) Empresa F & Reutilização e Reciclagem \\
\hline 7) Empresa G & Não pratica esse Processo \\
\hline 8) Empresa H & Não pratica esse Processo \\
\hline
\end{tabular}

Buscando um melhor esclarecimento e complementação das informações, relacionadas ao Quadro 7, se fez necessário coletar dados secundários provenientes de outra fonte de pesquisa a partir de entrevista com a empresa de reciclagem dos aparelhos televisores, peças e componentes, conforme segue.

Assim, foi realizada uma entrevista com o proprietário de uma empresa prestadora de serviços em coleta de sucatas de televisores e demais componentes eletrônicos e afins. Com atuação de mais de 10 anos na cidade de Franca. 0 mesmo pediu anonimato afirmando que seria por motivos de interesses de terceiros, podendo haver implicações diretas relacionadas à sua pessoa e uma potencial retaliação.

Neste sentido, a coleta de dados foi realizada a partir de um roteiro de entrevista, com seis questões (Tabela 8).

Tabela 8. Roteiro de entrevista.

\begin{tabular}{|l|l|}
\hline \multicolumn{1}{|c|}{ Perguntas } & \multicolumn{1}{c|}{ Respostas } \\
\hline $\begin{array}{l}\text { Como é o processo de } \\
\text { coleta dos televisores? }\end{array}$ & $\begin{array}{l}\text { A coleta é realizada com veículo próprio e a mesma é feita em } \\
\text { qualquer local desde que haja conveniência para a prática de algum } \\
\text { tipo de reaproveitamento. }\end{array}$ \\
\hline $\begin{array}{l}\text { Emquais empresas é } \\
\text { realizada a coleta? }\end{array}$ & $\begin{array}{l}\text { A coleta é realizada em escolas, repartições públicas, bancos, locais } \\
\text { privados desde que haja acesso autorizado. }\end{array}$ \\
$\begin{array}{l}\text { Qual a destinação dos } \\
\text { televisores? }\end{array}$ & $\begin{array}{l}\text { Após haver uma triagem para a prática de reutilização dos } \\
\text { componentes e peças os resíduos restantes são destinados a um } \\
\text { parceiro que estoca esses resíduos para descarte no aterro sanitário } \\
\text { da cidade. }\end{array}$ \\
\hline $\begin{array}{l}\text { Há Conhecimento do } \\
\text { Processo de Logística } \\
\text { Reversa? }\end{array}$ & $\begin{array}{l}\text { Possui um pouco de conhecimento e afirma que muitos fabricantes } \\
\text { atuantes em Franca cobram valores exorbitantes para coletar dos } \\
\text { lojistas, prestadores de serviços e lojas os resíduos que eles mesmos } \\
\text { colocaram no mercado em forma de produto. }\end{array}$ \\
\hline Há conhecimento da PNRS? & $\begin{array}{l}\text { Na cidade de Franca não existe a prática desta política, e a mesma } \\
\text { ainda está só descrita no papel. }\end{array}$ \\
\hline $\begin{array}{l}\text { Quais as ações aplicadas } \\
\text { referentes à política dos } \\
\text { 3R's? }\end{array}$ & $\begin{array}{l}\text { O mais relevante é a reutilização de placas de televisores, } \\
\text { computadores, fios elétricos, placas de micro-ondas e demais } \\
\text { componentes eletrônicos que podem ser reutilizados de alguma } \\
\text { forma gerando valores. }\end{array}$ \\
\hline
\end{tabular}


Através do roteiro de entrevista foi possível verificar que o entrevistado pratica a coleta dos materiais com veículo próprio, em vários locais fazendo a triagem e reaproveitamento de alguns componentes de televisores e outros equipamentos.

Após responder as devidas questões o entrevistado pediu também para que fossem registradas algumas observações, sendo elas:

\begin{abstract}
- Os resíduos dos televisores e equipamentos eletrônicos considerados irrelevantes são enviados para um deposito de ferro velho e não tem outro destino conhecido que não seja o aterro sanitário da cidade;

- 0 entrevistado tem conhecimento de proprietários de ferro velho localizado próximo a nascentes que deveriam ser protegidas e que mesmo assim depositam nesses locais produtos químicos tóxicos desconsiderando com a causa ambiental e revela que presenciou o derramamento desses produtos não intencionalmente, mas de forma irresponsável contaminado o lençol freático;

- Fios elétricos são juntados em grande quantidade em local menos visíveis para que possa ser realizada a queima e limpeza do cobre e o mesmo é comprado novamente pelo fabricante. Sendo esse um processo constante, libera gases nocivos à saúde humana, mas isso não é considerado;

- Os catadores de sucata em sua maioria são idosos acima dos 70 anos, também existem préadolescentes por volta dos 12 anos executando essa tarefa árdua.
\end{abstract}

Portanto, com a pesquisa de campo, foi possível visualizar a confirmação de que a aplicação da política dos 3R's reduzir, reutilizar e reciclar que está diretamente em acordo com a Política Nacional de Resíduos Sólidos, mostrou-se deficitária quanto à redução e reciclagem dos materiais em todas as empresas pesquisadas. Definiu- se que $50 \%$ das empresas pesquisadas praticam a reutilização, $25 \%$ das empresas praticam reutilização e reciclagem e $25 \%$ das empresas não praticam nenhum processo, sendo essa uma informação não menos que preocupante para um atual cenário de consumismo.

Neste contexto a aplicação da logística reversa em algumas destas empresas é um simples sistema de transporte dos resíduos sólidos. A aplicação dos da política dos 3 R's não é aplicada como deveria, falta uma educação ambiental por parte da maioria das empresas pesquisadas. Também falta uma melhor posição dos órgãos competentes em fiscalizar atividades suspeitas de violação ambiental.

Ainda, pode-se constatar junto ao processo de coleta de aparelho televisores e componentes que este está sendo realizado de forma inadequada, se levados em consideração o gerenciamento correto dos resíduos coletados em repartições públicas, escolas e empresas privadas. Até mesmo o fabricante não tem cooperado com os lojistas para que seja feita a prática correta da logística reversa e prática da política dos 3R's, cobrando dos mesmos valores altos para fazer a coleta dos resíduos mesmo sabendo que eles como fabricantes são responsáveis por essa coleta.

Além disso, resíduos estão depositados próximos a nascentes, contaminado o lençol freático, produto químicos armazenados no mesmo local contribuindo para a contaminação do lençol freático, queimam materiais liberando gases nocivos, e ainda existe a prática de trabalho infantil no mesmo cenário.

\section{Considerações finais}

Após a elaboração e finalização deste trabalho, pode-se considerar que os objetivos propostos nesta pesquisa foram alcançados de forma objetiva. mostrando os processos de aplicação da 
logística reversa, e da política dos 3 R's nos resíduos sólidos de produtos eletrônicos gerados na cidade de Franca.

Levando em consideração a preocupação com o meio ambiente, esta pesquisa está relacionada com a política dos 3 R's, aplicada à gestão dos resíduos dos televisores em Franca, tendo grande relevância ao mostrar que se houver a prática da redução no consumo, pode-se reduzir o uso de matéria prima, bem como verifica-se que a reutilização e a reciclagem é uma forma eficiente para proporcionar ganhos significativos no processo produtivo, melhorando produtos e contribuindo com a questão socioambiental.

Assim, o objetivo deste trabalho é reconhecer a logística reversa como forma de gestão dos resíduos de produtos de pós-consumo, em especial, os componentes de televisores e identificar a aplicação da política dos 3R's como proposta de gerenciamento de resíduos dos televisores em empresas de Franca. Considera-se, portanto, que este trabalho ajudou a contribuir para verificar que a logística reversa tem por objetivo viabilizar o reaproveitamento de matérias prima utilizadas em processos industriais, com a afirmativa de que com essa pratica haverá um ambiente saudável como foco na preservação ambiental.

Observando então as normas e regulamentos vigentes, quanto à redução, reutilização e reciclagem, a pesquisa de campo realizada foi fundamental para observância da prática de ações que contribuem, ou não com a Lei estabelecida, praticando a verificação de conformidades teóricas, exigidas para haver um consenso ético que está em falta quando a lucratividade compete diretamente com o meio ambiente.

Se após anos da implantação da Política Nacional dos Resíduos Sólidos ainda não ouve devida adequação por parte das empresas, isso significa que valores financeiros ainda são mais reconhecidos do que os valores ambientais.
Sobre a logística reversa, pode-se registrar que esta é aplicada informalmente, pois não há um planejamento adequado da coleta de televisores, bem como o seu retorno aos estabelecimentos comerciais, ou ainda, às indústrias. Pois, o que se tem é uma simples atividade de transporte aplicada aos televisores e componentes dos estabelecimentos que os recebe até um centro para triagem, não possuindo de estrutura adequada reversa para 0 correto gerenciamento dos resíduos gerados.

Também, é preciso destacar sobre a falta de gerenciamento dos resíduos sólidos dos aparelhos televisores, visto que são destinados de forma incorreta indo parar no aterro sanitário, produtos químicos tóxicos estão sendo dispostos junto a esses resíduos contaminando o lençol freático, queimam fios elétricos em grande quantidade para o reaproveitamento do cobre liberando gases nocivos à saúde humana e atrelado a essas práticas existem também a prática do trabalho infantil.

Constatou-se que a legalidade e preceitos da legislação não estão sendo plenamente compridos na cidade de Franca em relação aos aparelhos televisores e seus componentes, é provável que isso ocorra devido à falta de uma fiscalização séria e competente, facilitando a ação de pessoas com maior interesse financeiro e menor interesse ambiental. Tal situação não prejudica somente o meio ambiente, mas também, compromete a capacidade de rever valores sócios ambientais importantes para a cada geração.

Considera-se como solução em um primeiro momento ,a necessidade de haver uma educação ambiental por parte das empresas envolvidas, para aplicar a logística reversa e a apolítica dos 3 R's, e colocar em prática a responsabilidade do poder público em fiscalizaras ações de empresas sem gestão ambiental, e incentivar as mesmas que procurem cumprir as normas de licenciamento 
ambiental, gerando contratos de parcerias e expansão, atrelada a um sistema de melhoria continua na prática da logística reversa e gestão ambiental.

\section{Declaração de conflito de interesses}

Os autores declaram não haver conflito de interesses.

\section{Referências}

ABRELPE - Associação Brasileira de Empresas de Limpeza Pública e Resíduos Especiais. Panorama dos Resíduos Sólidos no Brasil 2015. Disponível em: <http://www.abrelpe.org.br/Panorama/pan orama2015.pdf>. Acesso em: 11 mar. 2017.

Albuquerque, J. L. Gestão ambiental e responsabilidade social: conceitos, ferramentas e aplicações. São Paulo: Atlas, 2009.

Arrigone, G. M.; Mutti, C. N.; Ferroli, P. C. M.; Librelotto, L. I. Geração de energia a partir de resíduos urbanos: coleta e tratamento, exemplos do norte da Itália. Mix Sustentável, v. 1, p. 10-24, 2015. Disponível em: <http://mixsustentavel.paginas. ufsc.br/files/2015/08/ARTIGO-1.pdf>.

Acesso em: 10 maio 2017.

Ballou, H. Logística empresarial: transportes, administração de materiais e distribuição física. 1. ed. São Paulo: Atlas, 2010.

Brasil. Resolução CONAMA no 01, de 23 de janeiro de 1986. Disponível em: <http://www.mma.gov.br/port/conama/legi slacao/CONAMA_RES_CONS_1986_001.pdf>. Acesso em: 12 mar. 2017.

Brasil. Ministério do Meio Ambiente. Princípio dos 3R's. 2017. Disponível em: <http://www.mma.gov.br/component/k2/it em/7589? Itemid=849>. Acesso em: 06 maio 2017.

Brasil. Lei no 12.305, de 2 de agosto de 2010. Institui a Política Nacional de Resíduos Sólidos; altera a Lei $\mathrm{n}$ - 9.605, de 12 de fevereiro de 1998; e dá outras providências. Disponível em: <http://www.planalto. gov.br/ccivil_03/_ato2007-

2010/2010/lei/l12305.htm>. Acesso em: 29 abr. 2017.
Dias, R. Gestão ambiental: responsabilidade social e sustentabilidade. 2. ed. São Paulo: Atlas, 2011.

Franca. Lei $\mathbf{n}^{\circ} 8.435$, de 14 de setembro de 2016. Plano municipal de gestão integrada de resíduos sólidos urbanos do município de Franca-SP. Disponível em: <http://www. franca.sp.gov.br/arquivos/diariooficial/documentos/608-17092016.pdf>. Acesso em: 05 maio 2017.

Gerbase, A. E.; Oliveira, C. R. Reciclagem do lixo de informática: uma oportunidade para a química. Química Nova, v. 35, n. 7, p. 1486-1492, 2012. https://doi.org/ 10.1590/S0100-40422012000700035

Guarnieri, P.; Dutra, D. J. S.; Pagani, R. N.; Hatakeyama, K.; Pilatti, L. A. Obtendo competitividade através da logística reversa: estudo de caso em uma madeireira. Journal of Technology Management \& Innovation, v. 1, n. 4., p. 121-130, 2006. Disponível em: <http://www.jotmi.org/index.php/GT/articl e/view/cas2/371>. Acesso em: 11 mar. 2017. Instituto Akatu. Será que isso vai para a reciclagem? São Paulo: Instituto Akatu, 2011. Disponível em: <https://www.akatu.org.br/noticia/seraque-isso-vai-para-a-reciclagem/>. Acesso em 29 abr. 2017.

IBGE - Instituto Brasileiro de Geografia e Estatística. Pesquisa Nacional por Amostra de Domicílios PNAD Suplementar 2013: acesso à Internet e à televisão e posse de telefone móvel celular para uso pessoal. Rio de Janeiro: IBGE, 2015. Disponível em: <http://www.ibge.gov.br/home/presidencia /noticias/imprensa/ppts/00000021542204 122015225529461268.pdf>. Acesso em: 10 maio 2017.

Leite, P. R. Logística reversa: meio ambiente e competitividade. São Paulo: Pearson Prentice Hall, 2009.

Lacerda, L. Logística reversa: uma visão sobre os conceitos e as práticas operacionais. Rio de Janeiro: COPPEAD/UFRJ, 2002. Disponível em: <http://www.paulo rodrigues.pro.br/arquivos/Logistica_Reversa _LGC.pdf>. Acesso em: 18 mar. 2017.

Machado, G. B. Portal dos resíduos sólidos. Disponível em: <http://www.portalresiduos solidos.com/>. Acesso em: 10 maio 2017.

Marconi, M. A.; Lakatos, E. M. Técnicas de pesquisa: planejamento e execução de pesquisas, amostragens e técnicas de 
pesquisa, elaboração, análise e interpretação de dados. 7. ed. São Paulo: Atlas, 2011.

Moura, L.A.A. Qualidade e gestão ambiental: sustentabilidade e implantação da ISO 14.001. 5 ed. rev. atual. São Paulo: Juarez de Oliveira, 2008.

Paoleschi, B. Logística industrial integrada: do planejamento, produção, custo e qualidade à satisfação do cliente. 1. ed. São Paulo: Érica, 2008.

Trigueiro, A. O lixo que vira energia. Mundo Sustentável. 2013. Disponível em: $<$ http://g1.globo.com/platb/mundosustentavel/2013/03/01/o-lixo-que-viraenergia/>. Acesso em: 10 maio 2017. seja devidamente citada. 